\title{
Review \\ Neuroscience needs ethology: the marked example of the moth pheromone system
}

\author{
Hervé Thevenon ${ }^{1}$ \\ 1 Affiliation: Spascia; herve.thevenon@spascia.fr \\ 2 Correspondence: herve.thevenon@spascia.fr
}

\begin{abstract}
The key premise of translational studies is that knowledge gained in one animal species can be transposed to other animals. So far translational bridges have mainly relied on genetic and physiological similarities, in experimental setups where behaviours and environment are often oversimplified. These simplifications were recently criticised for decreasing the intrinsic value of the published results. The inclusion of wild behaviour and rich environments in neuroscience experimental designs is difficult to achieve because no animal model has it all. As an example, the genetic toolkit of moths species is virtually non-existent when compared to C. elegans, rats, mice, or zebrafish, however the balance is reversed for wild behaviours. The ethological knowledge gathered about the moth was instrumental for designing natural-like auditory stimuli, that were used in association with electrophysiology in order to understand how moths use these variable sounds produced by their predators in order to trump death. Conversely, we are still stuck with understanding how male moths make sense of their complex and diffuse olfactory landscape in order to locate conspecific females up to several hundred meters away, and precisely identify a conspecific in a sympatric swarm in order to reproduce. This systemic review articulates the ethological knowledge pertaining to this unresolved problem and leverages the paradigm to gain insight into how male moths process sparse and uncertain environmental sensory information.
\end{abstract}

Keywords: moth; pheromone; noctuid;

\section{Introduction}

Starting 1 hour after dusk, females of the noctuid moth species fly for 15 to 30 minutes, land on crops, rest close to the flowers, and emit pheromones for a while. Males of the noctuid moths are known to flock toward the females upwind from as far as a few hundreds metres away. Despite different species of noctuid may be found on the same crops, and despite them sharing the same sex pheromones, males choose females from their species. When a male finds a female, they usually mate [1] and the female lays eggs in the flower to provide the future larvae with a food source: the future grains. Every 3 to 4 hours the group of females takes off again, crosswind. This cycle is repeated a few times during the night. As the moths go through their reproduction process, the crops may get pollens from other crops and increase their genetic capital. Ecological pressures kept the system in balance until intensive agriculture became prevalent.

The olfactory system of the moths has been studied for decades, most of it with the practical goal to increasing crop yield. The rationale was that the understanding of the olfactory system of the male should allow to engineer a means to disrupt the mating in order to avert the destruction of grains by the moth larvae, and therefore increase the yield. In the US, cotton yield per acre doubled between 1940 and 1960 [2]. The labs who were not working toward this goal considered the male moth as a potential translational animal model for neuroscience. This latter research led to identify the olfactory glomeruli and potential circuits that participate in the processing of the olfactory information, however we have no understanding of what the glomeruli do at any stage of the male's flight. 
This paper reviews and organises the knowledge gathered around the broadcast signalling system that allows female moths to keep attracting conspecific males during their period of fecundity. In section 2 we will look into several aspects of the production of pheromones, from wild female behaviours to pheromones secretion and dispersion in the atmosphere. In other words, we will ask when, where, how, and how much pheromones are emitted by a female and by a swarm. In section 3 , we will present how the cloud of pheromones emitted by a swarm of females evolves over time in the atmosphere, both before it reaches a male, and while males fly through it towards the swarm. In section 4, we will look into how the olfactory capabilities of the males can make sense of the atmospheric pheromone content they sense when flying toward a calling swarm. All together, these parts should provide the reader an overview of the moth pheromone system.

References focus on various species from the Noctuoidea superfamily as to constrain the anatomical diversity to a meaningful subset. As the data is patchy, a number of assumptions and ancillary materials are proposed to allow for an uninterrupted presentation of pheromone system.

Finally, we will sometimes focus on the complexities the male moth meets with regards to the characteristics of the female emitted pheromones as a means to check the consistency of the data collected on the moth pheromone system. Indeed, considering that the pheromone system we observe today was incepted 150 million year ago and co-evolved for males and females amongst sympatric species, there must exist some robust relationships between the characteristics of the pheromones emitted by a swarm of females and the characteristics of the males's olfactory organs.

\section{Pheromones: how, when, where are they produced?}

\subsection{The wild behaviour of female moths}

Starting 1 hour after dusk, Heliothis virescens females fly for 15 to 30 minutes, land on crops, rest close to the flowers, and emit pheromones intermittently for no more than 3 hours - "the calling" [3]. After the resting period, the females take off again with a stereotypical crosswind flight direction. The whole cycle is 3 to 4 hours long and repeats several times every night. The population moves together at ground speed up to $8 \mathrm{~m} / \mathrm{s}$. Swarms of flying females are dense and large enough - approximately 400 meters in diameter - to be detected with marine radars [3]. The literature provides no direct information about the number of individuals in the swarms, however the headcount may be approximated from the density of calling swarms and the size of the crops.

A rare density survey concerns the female population of Gipsy moth (Lymantria dispar) in oak tree canopies that was found to be 1,000 to 6,000 females per $10,000 \mathrm{~m}^{2}$ [4]. It is easy to be confused with the more abundant larvae surveys. Reported larvae population in 1963 is 1,200 per acre1 of cotton for Heliothis virescens and up to 2,900 for Helicoverpa zea [5]. Larvae populations vary greatly per crops; another survey found up to 14,000 larvae per acre during the year. However all these figures contribute to form a consistent picture.

The conditions met by the male cotton-loving moth species changed dramatically in the US between 1920 and 1960. Cotton crops appeared in the early 20's in farms predominantly small and non-mechanised. At the other end, the acreage was at its peak in the $60^{\prime} \mathrm{s}$ in farms predominantly large with a high level of mechanisation. The literature was searched extensively to find the average size of a cotton or corn fields in the 1960's in order to link the data to Lingren and Wolf's paper. Clues were found in the Carolinas (East coast of the USA, above the southern states) where the traditional cotton and corn crops were "patches" of only a few acres carved out of the encircling woods [6]. This picture fits well with Lingren's radar images.

The Carolinas are on the Eats coast, while Lingren's Arizona is closer to the West coast. The West also produced much more cotton than the East. The typical cotton field of the East may have been

\footnotetext{
11 acre $=4,047 \mathrm{~m}^{2}$
} 
smaller than in the Southwest [7]. In Lingren's Arizona, a swarm is a 400 metre diameter disc, therefore its surface is approximately $125,000 \mathrm{~m}^{2}$, i.e. 30 acres. A 30 acres field is definitely larger than the few acres of the Carolinas. It is also consistent with an average farm size of 300 acres [8]. From these elements, it seems reasonable to consider that one of the natural targets of the male moth is a $125,000 \mathrm{~m}^{2}$ field, with 12,500 to 75,000 females2 calling intermittently over a 3-hour period. These figures are consistent with the previously reported density of the Gipsy moth, and provide us with an approximate density of a landed swarm: $0.35 \pm 0.25$ female per square meter.

Depending on the species, calling starts on the first or second day after hatching, and sexual maturity requires up to 5 nights $[9,10]$.

\subsection{Moth pheromones: blends, attractants and deterrents}

The Encyclopaedia of Ecology [11] mentions that "377 pheromone components have been described for about 1500 species of moths in 2006". The identification of the different molecules produced by the sex pheromone gland of females of various species preceded the identification of the components that elicit male positive taxi toward conspecific females, and the identification of the components that contribute to species isolation [11-13].

Taking Heliothis virescens as an example, six different molecules may be extracted from the sex pheromones gland (table 1) [12, 14, 15]. The differences in the papers may be explained by both the differences in equipment and methods used, and the inherent variability between conspecifics.

Table 1. Composition of the mixture extracted from the pheromone gland of Heliothis v.

\begin{tabular}{|c|c|c|c|}
\hline & Pope, Gaston et al, 1984 & Teal, Tumlinson et al, 1986 & $\begin{array}{l}\text { Heath, Mc Laughlin et al. } \\
1991 \text { Mississipi (reared) }\end{array}$ \\
\hline Z11-16:Ald & $74.0 \%$ & $79.5 \%$ & $73.3 \%$ \\
\hline Z9-14:Ald & $0.3 \%$ & $3.3 \%$ & $4.8 \%$ \\
\hline Z7 -16:Ald or/and Z9-16:Ald & $2.1 \%$ & $0.8 \%$ & $1.4 \%$ \\
\hline $\mathrm{Z} 11-16: \mathrm{OH}$ & $4.2 \%$ & $4.7 \%$ & $11.2 \%$ \\
\hline Z7-16:Ald & & $0.6 \%$ & \\
\hline other-16:Ald & $18.9 \%$ & $8.6 \%$ & $6.8 \%$ \\
\hline \multirow[t]{2}{*}{ other-14:Ald } & $0.5 \%$ & $2.5 \%$ & $2.6 \%$ \\
\hline & $100.0 \%$ & $100.0 \%$ & $100.0 \%$ \\
\hline
\end{tabular}

When reading tables of extracted compounds, one must keep in mind that the molecules produced by the females are derived from fatty acids widely found across moths species and across numerous biosynthetic pathways [16-19]. There are several important implications: (i) some of the molecules found may be intermediary products, (ii) some may not be volatile (i.e. not emitted), (iii) some may be the byproducts of imperfect chemistry.

Another important observation is that the females do not produce a constant distribution of each molecule over time. This implies that one should not visualise the produced pheromones as filaments as sometimes suggested [20]. A better picture is a system of particles moved by a forced air flow.

Examples of the attractive blends and deterrent in sympatric species are provided in table 2 [2126]. According to this table Z9-14:Ald produced by female Heliothis virescens and Heliothis peltigera is a deterrent for the males of 3 other species.

\footnotetext{
${ }^{2}$ as per section 1.1
} 
Table 2. Examples of the attractive blends and deterrent in sympatric species.

\begin{tabular}{|c|l|c|c|c|c|}
\hline $\begin{array}{c}\text { Sympatric } \\
\text { groups }\end{array}$ & Species & Z11-16:Ald & Z9-14:Ald & Z9-16:Ald & Z11-16:Ac \\
\hline \multirow{2}{*}{ A } & Heliothis virescens & ++ & + & & - \\
\cline { 2 - 6 } & Helicoverpa zea & + & - & + & \\
\hline \multirow{3}{*}{$\mathrm{B}$} & Helicoverpa assulta & + & - & ++ & \\
\cline { 2 - 6 } & Heliothis peltigera & + & + & & \\
\cline { 2 - 7 } & Helicoverpa armigera & ++ & - & + & \\
\hline
\end{tabular}

"++" indicates the dominant attractant for the males of the species, "_" indicates the deterrent.

The existence of such deterrent in sympatric species adds another perspective to what males might be able to do in real settings: to distinguish a conspecific from heterospecific females within a few square metres. There is indeed an additional layer of complexity that should be added to table 2 . While high levels of Z9-14:Ald are deterrent for Helicoverpa armigera, it was also found that low concentrations (up to 3\%) makes it an attractant (toward its conspecific female) [27-29]. This means males may need to discriminate relative concentrations both positively and negatively for some or all of the pheromones they can sense.

\subsection{Diffusion of the pheromones: the pheromone gland}

The female moth produces the set of conspecific-attractant and heterospecific-deterrent molecules with a gland carried by the dorsal side of the 9th abdominal segment [26, 30, 31]. This last segment is usually folded inside the two previous segments. It is temporarily unfolded and extended out in the air during the calling period. The following diagram shows the "telescoping" of the 8th and 9 th abdominal segments within the 7 th (Figure 1).

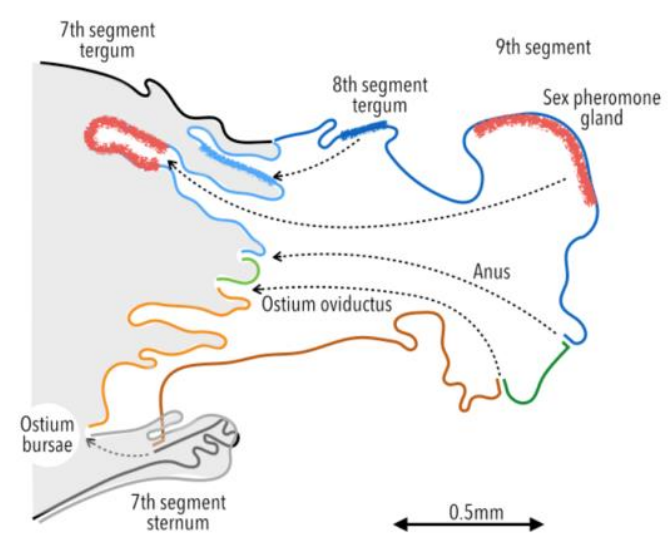

Figure 1. Location of the sex pheromone gland when the 8th and 9th segments are retracted in the abdomen (in grey), and when extruded (in white).

The process that allows the molecules of pheromones to pass from the pheromone gland to the surrounding volume of air is called diffusion. Physical models of diffusion and evaporation [32-34] predict that different molecules will pass into the air at different rates. The actual geometry of the gland is important to understand in order to calculate these diffusion rates. Calculations performed with the physical models above are in accord with reports mentioned previously [12, 15] for Heliothis virescens and collated in table 3. 
Table 3. Composition of the volatile pheromones emitted by females Heliothis v.

\begin{tabular}{|c|c|c|c|c|c|c|c|}
\hline & \multicolumn{2}{|c|}{ Pope, Gaston et al, 1984} & \multicolumn{2}{|c|}{ Teal, Tumlinson et al, 1986} & \multicolumn{3}{|c|}{$\begin{array}{r}\text { Heath, Mc Laughlin et al. } 1991 \\
\text { Mississipi (reared) }\end{array}$} \\
\hline & ng/min & $\begin{array}{r}\text { percentage of } \\
\text { the mixture }\end{array}$ & $\mathrm{ng} / \mathrm{min}$ & $\begin{array}{r}\text { percentage of } \\
\text { the mixture }\end{array}$ & ng/hour & $\begin{array}{r}\mathbf{n g} / \mathbf{m i n} \\
\text { (calculated) }\end{array}$ & $\begin{array}{r}\text { percentage of } \\
\text { the mixture }\end{array}$ \\
\hline Z11-16:Ald & 1.85 & $86.4 \%$ & 0.78 & $60.0 \%$ & 12.3 & 0.21 & $56.4 \%$ \\
\hline Z9-14:Ald & 0.09 & $4.2 \%$ & 0.24 & $18.1 \%$ & 4.2 & 0.07 & $19.3 \%$ \\
\hline $\begin{array}{r}\text { Z7 -16:Ald or/and Z9- } \\
16: \text { Ald }\end{array}$ & 0.04 & $1.9 \%$ & 0.02 & $1.6 \%$ & 0.1 & 0.00 & $0.5 \%$ \\
\hline other-16:Ald & 0.1 & $4.7 \%$ & 0.09 & $7.3 \%$ & 2.7 & 0.05 & $12.4 \%$ \\
\hline other-14:Ald & 0.06 & $2.8 \%$ & 0.17 & $13.0 \%$ & 2.5 & 0.04 & $11.5 \%$ \\
\hline Total & 2.14 & $100 \%$ & 1.30 & $100 \%$ & 21.8 & 0.36 & $100 \%$ \\
\hline
\end{tabular}

Both the quantities and composition of the pheromones emitted during calling are different from extracted glands. The quantities vary during a 24-hour period, within the scotophase itself, and with the atmospheric conditions (e.g. temperature, pressure). Table 3 shows the distributions reported by three experiments that measured the natural airborne emission from females in forced air flow at different temperatures. [21,24] concluded that Z11-16:Ald and Z9-14:Ald are sufficient to elicit flight in the male. Both lines are highlighted.

The composition of the mixture as reported by Pope and Gaston seems inconsistent with the two others, and with reports on other species. The structure of the mixtures usually fits a major/medium/minor pattern instead of a major/minor/minor structure as reported by Pope and Gaston.

\subsection{Secretions versus emissions}

We note the emitted percentages differ widely between secretion (table 1) and emission (table 3). The emitted and secreted quantities of Z11-16:Ald and Z9-14:Ald are compared in the form of ratios in table 4 .

Table 4. Ratios of the quantities measured for Z11-16:Ald and Z9-14:Ald, when secreted and emitted

\begin{tabular}{|c|c|c|c|c|c|c|}
\cline { 2 - 7 } \multicolumn{1}{c|}{} & \multicolumn{2}{|c|}{ Pope, Gaston et al, 1984 } & \multicolumn{2}{c|}{ Teal, Tumlinson et al, 1986 } & \multicolumn{2}{c|}{$\begin{array}{c}\text { Heath, Mc Laughlin et al. } \\
\text { 1991 Mississipi (reared) }\end{array}$} \\
\cline { 2 - 7 } & secreted & emitted & secreted & emitted & secreted & emitted \\
\hline Z11-16:Ald : Z9-14:Ald ratio & 246.67 & 20.56 & 24.09 & 3.31 & 15.38 & 2.93 \\
\hline
\end{tabular}

Table 4 shows large differences between secretion and emission ratios that call for an explanation. The alternated secretion and emission hypothesis can be rejected offhand as continuous secretions have been observed during the scotophase (all 3 papers) and over a 24 hours period [35]. Alternate hypotheses are:

- over-secretion and under-emission of pheromones induced by the method,

- equipment induced errors,

- $\quad$ an asymmetric production/emission cycle: pheromones could be heavily produced and stored when females are at the beginning of their adult life, and released slowly over the rest of the lifespan. This is a testable hypothesis that has not been investigated yet.

- a proprioceptive feedback mechanism that regulates the gene expression that leads to the differentiation of the molecules produced. The olfactory basis of that hypothesis was tested on the Silk moth [36] and rejected. However the Silk moth has been domesticated for a long time, 
and that result should not deter further investigations on non-domesticated species. The structural olfactory resources of the females from several other species have been investigated [37-40]. Finally it must be noted that a proprioceptive mechanism that regulates the production of pheromones doesn't necessarily require an olfactory mechanism: hormonal [41] and genetic self-regulation mechanisms are defendable hypotheses.

Table 4 also shows a large discrepancy between Pope's experiment and the two others, both for secreted and emitted quantities of both molecules. Consequently we will focus on Teal's and Heath's figures in order to evaluate the rate of molecules let in the air by a female over time. Considering there's a factor x3.5 between Teal and Heath's emission figures for Z11-16:Ald and Z9-14:Ald (table 3 / highlights), we can tentatively interpret them as a min-max range.

\subsection{Relationship between the calling-resting cycle and bursts and the size of a swarm}

It is important to consider the effect of the calling-resting cycle on the concentration of the pheromones that may be found in the atmosphere. Indeed, at the same level of pheromone release, long callings would overlap and create a denser concentration at long distance, while short callings would barely overlap and result in a weaker concentration less detectable at the same distance.

A study performed on the Gipsy moth [42] showed that wild females emit a single 30 minutes burst in their lifetime, while lab reared females emit continuously at a much smaller rate. The actual difference is a factor 200. This 30 minutes wild burst is to be contrasted with a 10 days adult lifespan, that is 10 nights of calling for approximately 12 hours each night. Effectively the emission burst represents $0.4 \%$ of a female total calling time.

Alternatively we can understand this figure as: given a calling female, the probability it calls at burst level is $0.4 \%$. Given this figure, a swarm should consist of at least 250 conspecific females in order to emit a continuous concentration. Indeed it is unlikely that 250 females will coordinate their effort to produce a continuous flow, and it is more likely that their total emission will be patchy and wildly alternate between extremes.

A Monte-Carlo approach (figure 2) shows that populations of 12,500 to 75,000 females per swarm (section 2.1) would produce a rather constant emission rate. The maximum emission rate is reached within 1 hour after the calling starts; that is consistent with the females's 3 to 4 hours flying-restingcalling cycle. The minimum size of a conspecific swarm is likely to be around 1,000 females. Further 
investigations would be required to assess this number when sympatric hetero-specific females are

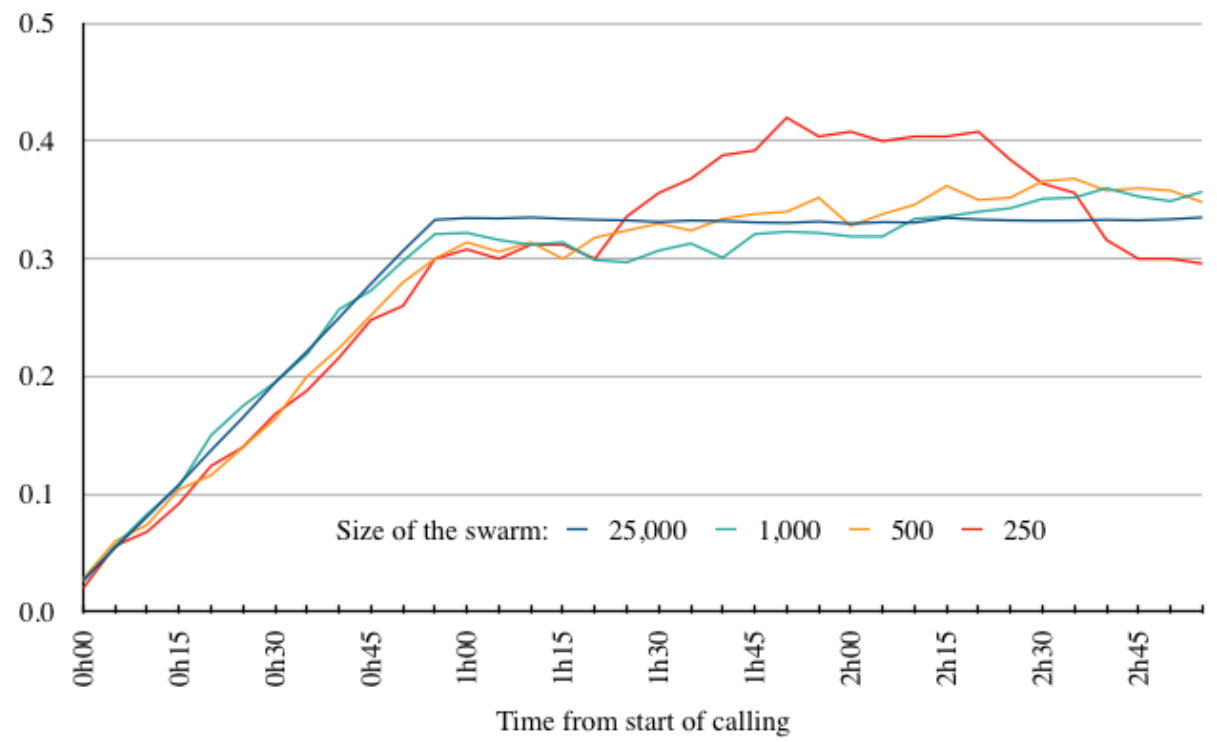

mixed together, as in a typical swarm.

Figure 2. Compounded effect of the given population of callers (arbitrary scale), with the call duration set to 30 minutes for all individuals.

While a few females will be bursting, the rest $-99.6 \%$ of the swarm - will emit at the approximate "residual" rate of $0.5 \mathrm{ng} / 30$ minutes [42]. The average emission of the swarm is therefore $0.004^{*} 500+0.996^{*} 0.5=2.5 \mathrm{ng} / 30$ minutes per female, or $0.0833 \mathrm{ng} /$ minute / female.

A single Gipsy moth female used as an attractant in a wind tunnel whose section is $7.8 \mathrm{~cm} \times 9 \mathrm{~cm}$ [42] releases $160 \mathrm{pg} / \mathrm{min}$ in a $0.007 \mathrm{~m}^{2}$ section, that is over $22 \mathrm{ng} / \mathrm{min} / \mathrm{m}^{2}$ i.e. 1,000 times more than in the wild. In other words, this is equivalent to a density of females per unit of surface multiplied by 1,000 . We have previously seen (section 2.2) that a pheromone can be both attractant or deterrent for the same species based on its concentration; a x1,000 difference could be responsible for conflicting results in wind tunnel experiments.

The pheromone release of the Gipsy moth in the wild [42] is the only study that addresses this topic. The results suggest that females fly together because they do not emit together.

\section{Atmospheric transport of the pheromones}

In this section we look at how the pheromones spread in the atmosphere when they leave the female glands, and what it may look like for a male moth flying upwind as it gets closer and closer from a swarm that hosts conspecific females.

As stated earlier, females don't emit pheromones in the same way when in captivity or in the wild. In captivity, individual females have been seen to emit for at least 6 hours. In the wild, females are in a swarm, approximately 400 meters diameter large, and they fly from one crop to another every 3 to 4 hours. Therefore wild females interrupt their emission to fly for up to 30 minutes to another crop, where they will rest then start calling again. Consequently, on the basis of the reports we have, wild calling is likely to last less than 3 hours. Lingren and Wolf also noted that the calling is intermittent during this window.

The female in captivity scenario and the wind tunnel experiments on the males are useful experimental devices, however they are intrinsically limited for they cut the animals from their 
natural environment. As animals are put in an environment that is different from their natural environment, they miss the stimuli produced by the environment - of which we know little - and may pick up stimuli that wouldn't be present in the wild. This is a well known issue with the design of experiments in comparative and human psychology. Simply put, we don't know what simplifications or complexities our experimental setups create with regards to the natural environment. That is why we need to look into what the pheromones emission created by a swarm may look like.

In this section we will focus on the bases of simulating the pheromone emission of a swarm: how long should we run the simulation for, and how can we assess the results before applying them to further investigations.

\subsection{Duration of the simulation: the male's challenge is short lived}

In the wild, it was observed that males stimulated by their female conspecific blend fly upwind at an average ground speed of $2 \mathrm{~m} / \mathrm{s}$ independently of the wind speed3 [23]. It was also observed that males take off when within 40 metres from the source [3]. Experiments involving traps suggest that the distance could be above 75 metres [43]. At the ground speed of $2 \mathrm{~m} / \mathrm{s}$, a moth will cross a 75 metres distance within 37 seconds.

We also know that males require a minimum wind speed of approximately $0.5 \mathrm{~m} / \mathrm{s}$ to get airborne, and that they slow down significantly when within 1 meter of their targets [23]. Basically, a male that flies for more than one minute is likely to visit a swarm that is not the closest one.

\subsection{Simulation complexities and simplifications}

A number of studies have produced dispersion models and assessed the dispersion of pheromones in the atmosphere [44,45]. In order to visualise the challenge faced by the moth, we may simulate the dispersion of pheromones created by one or several females in a windy environment [46-48]. A useful simulation would allow for both the windspeed and direction are allowed to vary over time, and for the concentration of pheromones to be measured anywhere downwind and crosswind as the sum of the different sources. The treatment of the vertical axis is complicated by the nightly release of heat and moisture from the soil and the crops. For the scope of this review, we may simplify it as equal to the crosswind axis. This is indeed completely inaccurate in the turbulences found around the crops, but acceptable a few metres above (laminar flow approximation).

In order to illustrate the matter at hand (see figure 3), a simulation was created and posted on the Open Science Framework. The simulation fluctuating_plume_based_swarm_simulation (https://osf.io/z46j7/) can be run on most operating systems (Linux, OS X, Windows) with Processing (https://processing.org). The gaussian dispersion approach that was used [46] fits with measurements in natural settings [44, 45]. Key variables of the simulation include a variable windspeed between $0.5 \mathrm{~m} / \mathrm{s}$ and $4 \mathrm{~m} / \mathrm{s}$, wind bearing between $-15^{\circ}$ and $+15^{\circ}$, and wind stability between 2 and 10 seconds.

${ }^{3}$ as long as the male can handle the windspeed. 


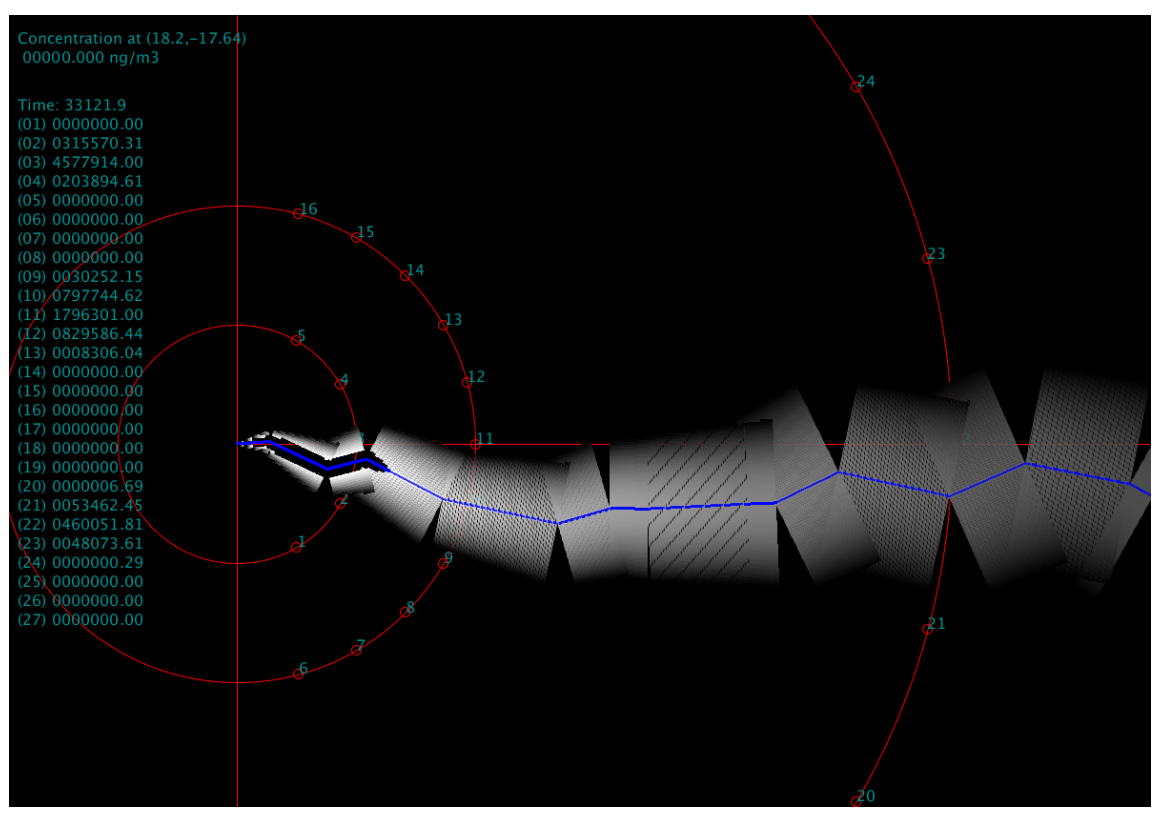

Figure 3. Simulation of the atmospheric dispersion of pheromones from a point source. This example shows the fluctuating plume (in white) dispersion model, in a changing wind (midline in blue), and the checkpoints used in $[44,45]$ (on the red concentric circles).

Figure 4 shows a bird's view snapshot of the simulation of a plume created by a single female over 150m downwind from the emission point (on the left; axes ticks are separated by 10 metres). Each white bar represents an infinitesimal puff, created at constant time intervals, with the same colour. The $y$-axis is associated with both the crosswind displacement of the puffs (at scale with the $x$-axis), and the spread of the puffs over time and distance (relative scale). The height of each bar is proportional to one standard deviation of the gaussian distribution model of the crosswind diffusion. The whiter the colour, the closer each infinitesimal puffs are from one another (due to slower wind when they were emitted), and the higher the concentration of pheromones per unit of volume. It should be noted that in each segment (of constant windspeed), the concentration consistently increases upwind.

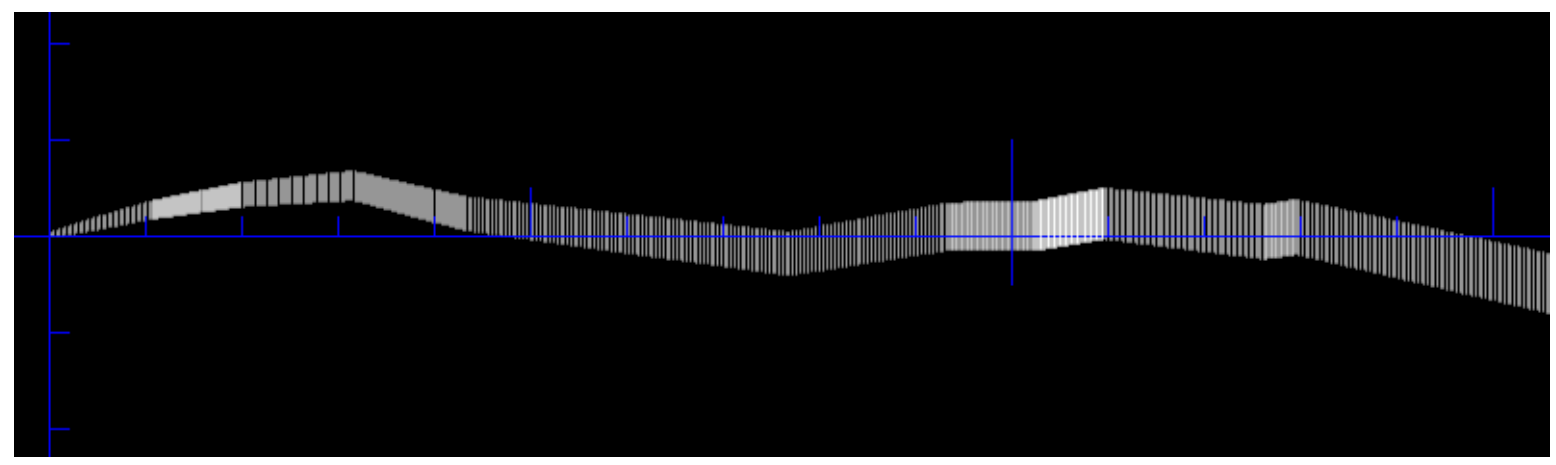

Figure 4. Simulation of the atmospheric dispersion of pheromones from a point source over 150m downwind. In this simulation, the segments are approximated as parallel, in order to simplify the calculations for a simulation involving more than a thousand point sources.

Indeed, one would expect that a male confronted to a brutal drop in concentration - by moving from a segment generated under a higher windspeed than the next one - has a behaviour wired to look for a better alternative. That is what might trigger the observed and simulated casting behaviour $[23,49]$ when pheromones are emitted from one point.

This single source simulation is close to what happens in wind tunnel experiments, but for the eddies that arise from constraining the air flow in a tunnel. In the wild, eddies may be found just above the crops, in the area where the flowers will catch the otherwise mostly laminar flow of the 
wind. Males will definitely experience some turbulences in the last metre(s) of their journey towards the females. However for most of the trip spent a few meters above the crops, it is safe to assume they navigate a rather homogenous and increasing gradient of pheromones.

Another difference between wind tunnel and wild conditions does relate to the combination of the individual plumes produced by all the females of the swarm: it forms a cloud. The previous simulation was scaled in order to visualise the pheromone cloud produced by a swarm. This second simulation features a source the size of a $350 \mathrm{~m} \times 20 \mathrm{~m}$ piece of cultivated land, with 1,450 randomly distributed females. The density of the landed swarm was arbitrarily taken on the lower side of the range stated in section 2.1, at 0.2 female per square meter.

A first order validation is provided by a representation of the puffs at the exit of the field (figure 5), i.e. 340m downwind, a few minutes after landing (established regime).

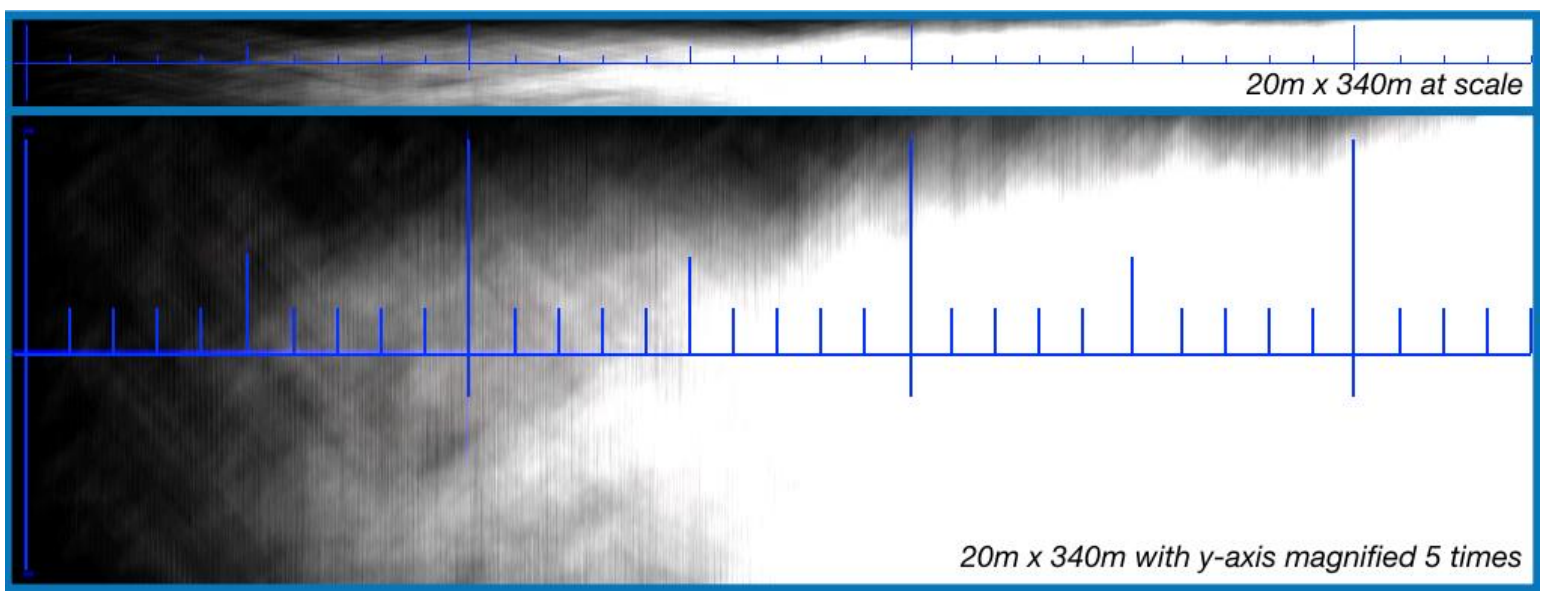

Figure 5. Simulation of the atmospheric dispersion of pheromones produced by a swarm of 1,450 females randomly located over a 350x20 sqm area.

The concentration of pheromones encountered while flying upwind towards the large source, at a $2 \mathrm{~m} / \mathrm{s}$ ground speed (when projected on the $\mathrm{x}$-axis), in a 2 metres crosswind strip, every $5 \mathrm{~cm}$ along both $\mathrm{x}$ and $\mathrm{y}$ axes (details in the code posted on the OSF repository), where the wind speed was allowed to vary between $0.5 \mathrm{~m} / \mathrm{s}$ and $5 \mathrm{~m} / \mathrm{s}$.

\section{Catching pheromones}

The male moth's only pheromones detection devices are two antennae covered with short hairs that catch molecules in the air and drive them to neurons that evolved as pheromone specific detector. Therefore this is the number of molecules caught by the antennae that may inform a male about the location of the swarm (together with the wind direction) and a conspecific female.

In this section we model the male moths olfactory organs as a comb that catches pheromone molecules, we rationalise observations that wild male moth always fly above a certain speed, and we demonstrate that the male moth integrates information over a minimum integration window in order to not be affected by inconsistencies in the pheromone field and get close to a conspecific while running on the attractant pheromone with the smaller emission rate.

\subsection{The male moths olfactory organs: a comb for pheromone molecules}

From Burns \& Teal [50] we learn that the antennae of the male Heliothis virescens are approximately $11 \mathrm{~mm}$ long, conical, and consists of 75 segments each on average. Along the antenna the diameter of the segments is $183 \mu \mathrm{m}$ for the base segment, $148 \mu \mathrm{m}$ for the mid segment, and $72 \mu \mathrm{m}$ for the tip. The same source puts 110 sensillae trichodea type 2 (reactive to pheromone) per segment from base to mid section, and 50 near the end. Therefore each antenna bears approximately 15,050 sensillae. The same source pictures sensillae and indicates their length varies from 20 to $100 \mu \mathrm{m}$. 
Almaas and Mustaparta [51] offer a consistent perspective, including for the distribution of type 1 and type 2 sensilla trichodea (12,000 in total per antenna - page 1337).

In the following we use the average of both sources and make a simplistic evaluation of the transversal surface of the antennae. The comb, i.e. the transversal surface of each antenna is a truncated triangle (figure 6) with the following dimensions:

- length: $11 \mathrm{~mm}$,

- base of the triangle: $183 \mu \mathrm{m}$ (base diameter) $+76 \mu \mathrm{m}$ (longest of type 1 sensillae)

- $\quad$ truncated end: $72 \mu \mathrm{m}$ (diameter) $+33 \mu \mathrm{m}$ (longest of type 2 sensillae).
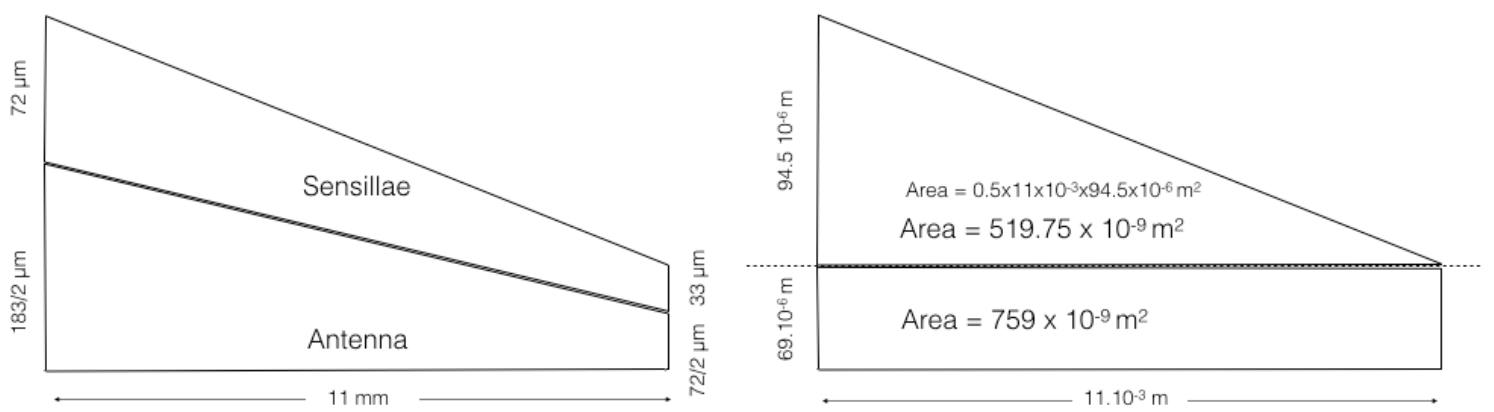

Figure 6. Approximation of the catchment area offered by an antenna.

The area of one antenna (rod + sensillae) may be evaluated by dividing it as shown on the drawing above. The resulting surface for a whole antenna is approximately $2.55710^{-6} \mathrm{~m}^{2}$.

The analogy of the comb works well whether it is hair or air being combed, because both feature a kind of sweep. When combing hair, the hand moves the comb through the hair, over and over again. In the case of the antenna-comb, the sweep can be considered as the succession of events that constitute the pheromone processing cycle $[52,53]$; according to Kaissling's papers, the whole process could take between $200 \mathrm{~m}$ and $500 \mathrm{~ms}$ :

- a molecule is caught by a sensilla during the flight,

- the molecule progresses down the sensilla,

- the molecule is degraded by enzymes,

- the result of the degradation may activate one of the olfactory receptor neurons grouped at the base of the sensilla ( 1 to 3 ORNs4 per sensilla),

- the action potential (if any) propagates along an axon within the antenna, and arrives to the antennal lobe,

- the base of the sensilla is cleaned as to allow another molecule to be processed,

- the firing neuron goes out of refractory period,

- time passes before another molecule is caught that can be processed end-to-end.

\subsection{From concentrations to molecules}

As noted in this section's introduction, the primary information sensed by the olfactory organs of the male moth is the number of molecules caught on its flight path, not the actual concentrations. The key to translating blends and masses into number of molecules is the molecular weights. Approximate molecular weights are derived from Z11-16:Ald and Z9-14:Ald respective formulas (table 5).

\begin{tabular}{|c|c|c|c|}
\hline Molecule & Linear representation & Compact & Molar weight (g/mol) \\
\hline Z11-16:Ald & $\mathrm{CH}_{3}\left(\mathrm{CH}_{2}\right)_{3} \mathrm{CH}=\mathrm{CH}\left(\mathrm{CH}_{2}\right)_{9} \mathrm{CHO}$ & $\mathrm{C} 16 \mathrm{H} 30 \mathrm{O}$ & 238 \\
\hline Z9-14:Ald & $\mathrm{CH}_{3}(\mathrm{CH})_{3} \mathrm{CH}=\mathrm{CH}\left(\mathrm{CH}_{2}\right)_{7} \mathrm{CHO}$ & $\mathrm{C} 14 \mathrm{H} 26 \mathrm{O}$ & 210 \\
\hline
\end{tabular}

\footnotetext{
${ }^{4}$ Also known as OSNs, for Olfactory Sensory Neuron.
} 
Table 5. Structure and molar weights of Z11-16:Ald and Z9-14:Ald

The number of molecules is obtained by dividing the mass of emitted molecules by the molecular weight and multiplying it by the Avogadro constant. As a complement to section 2.3, we note that both molecules have a similar structure, therefore evaporation and diffusion models surveyed [34,54-56] suggest the transfer of both molecules in the air should be in the same range.

\subsection{Male moths must fly above a certain speed limit}

Male moths take off when the airspeed is $1 \mathrm{~m} / \mathrm{s}$ and the principal element of the species specific blend raises above a certain threshold (reference). After take off, independently of the wind speed, the moth flies at a constant ground speed, that is approximately $2 \mathrm{~m} / \mathrm{s}$, until it reaches the swarm. (reference)

This observed constant ground speed while homing toward the swarm suggests male moths may need to catch a minimum of molecules to make sense of their olfactory environment. All car drivers know that the faster a car under the rain, the more water is caught by the windscreen. While motorists would definitely do without rain, moths may need a bare minimum of molecules to home on the swarm and on a conspecific. That bare minimum air speed is obtained with a minimum ground speed: $2 \mathrm{~m} / \mathrm{s}$.

\subsection{Long range integration window}

There are two thought patterns in the neuroscience literature: either a stimulus flows through the nervous system and should have a direct cascade impact that takes the form of an immediate action, either a number of stimuli are collected within a rather constant period of time before an action may be triggered: that's the concept of integration window. In this section we focus on testing the grounds for the integration window hypothesis when a swarm is being approached at long range.

In section 4.1 we mentioned that the chemical degradation and identification process of the male moth olfactory organ takes between 200 and $500 \mathrm{~ms}$ per molecule being caught by the antennae. In section 4.2 we provided a means to convert the key concentrations reviewed in section 2 into number of molecules, and we further confirmed that the differences between the molecules have a marginal effect on their diffusion (section 2.3) and dispersion (section 3). This makes the simulation developed in section 3 generalisable to all pheromones, at least in the first order of approximation. In section 4.3 we noted and rationalised observations that male moths always fly above a certain air speed while homing toward the swarm. Consequently this additional data may be applied to an imaginary moth flying the pheromone field simulated in section 3 in straight line toward the swarm, in order to determine how long the integration window may be.

The swarm simulation described in 3.2 was modified in order to assay the pheromone field with a male moth flying at the minimum airspeed discussed in section 4.3. Raw data was posted on the OSF repository (base 1 per calling female, and base 1000 for the bursting periods). Using the approximation that all pheromone molecules diffuse and disperse with marginal variations, this raw data was scaled to represent several pheromones at the same time.

For the long range study, we arbitrarily used the case of Heliothis virescens and the figures identified in section 2.5, for both major and medium attractants Z11-16:Ald (60\% of the whole blend) and Z9-14:Ald (20\%). The simulation being run covers the distance 50 to 40 meters away from the swarm (where males are known to kick off their journey toward the swarm). The effects of a potential integration window are derived for $100 \mathrm{~ms}, 200 \mathrm{~ms}, 500 \mathrm{~ms}$, and $1 \mathrm{~s}$. Given the approximate emission figure for a female in a swarm calculated in section 2.5, the simulation effectively develops an emission rate of i.e. $2.76610-13 \mathrm{~g} / \mathrm{ms} / \mathrm{sqm}$. This figure is used to translate concentrations in number of molecules actually combed by the moth (by using the combing surface of an antenna derived in section 4.1). Summary results are provided in table 6. 


\begin{tabular}{|r|r|r|r|r|}
\hline Integration window (ms) & $\mathbf{1 0 0}$ & $\mathbf{2 0 0}$ & $\mathbf{5 0 0}$ & $\mathbf{1 0 0 0}$ \\
\hline Relative variation in concentration & & & & \\
\hline Average & 0.03 & 0.07 & 0.21 & 0.41 \\
\hline Mtandard deviation & 0.10 & 0.14 & 0.31 & 0.36 \\
\hline Maximum & -0.44 & -0.27 & -0.25 & -0.13 \\
\hline $\begin{array}{r}\text { Average number of moleculs combed within } \\
\text { the integration window }\end{array}$ & & & & \\
\hline Z9-14:Ald (medium attractant) & 41 & 81 & 203 & 406 \\
\hline Z11-16:Ald (major attractant) & 107 & 215 & 537 & 1,074 \\
\hline
\end{tabular}

Table 6. Evaluation of the integration window based on a simulation with 1,450 females in a $350 \mathrm{~m} \times 20 \mathrm{~m}$ area (i.e. 0.2 female per sqm), based on raw emission factors (residual:burst = 1:1000)

Relative variations in concentration were calculated from the pheromone concentration field produced by the simulation (not scaled for any specific molecule). The averages and associated standard deviations confirm the intuition that the longer the integration window, the higher the chances for the male moth to not be caught in a decrease of the concentration while flying upwind. With a normal distribution the 1s integration window will provide the moth with a effective increase of pheromone intake approximately $70 \%$ of the time, while the $500 \mathrm{~ms}$ integration window would achieve it less than $50 \%$ of the time (the standard deviation is much larger than the average). Primarily, these results show that the intrinsic structure of a pheromone field weighs positively on the hypothesis that the nervous system of male moths samples the olfactory information it senses over time, or in other words, through the perspective of time bins.

These relative variations also provide an interesting perspective on the minimum ground speed (hence a minimum airspeed) that was observed in male male moths, and on the density of the swarm. A faster air speed will allow the moth to comb a greater volume of air, and consequently to catch a larger number of molecules. A denser swarm will structurally increase the number of molecules in the air, and may cause males to take off further from the swarm despite the dispersion's adversarial effect.

The corresponding average number of attractant molecules caught per integration window is provided to give some flesh to the relative variations. They are indeed proportional to the integration window, the flight speed, and the density of the swarm. Indeed they are to be put in relation with the number of sensillae per antenna $(\sim 15,000)$. Given a $100 \mathrm{~ms}$ integration window, the major attractant would be caught by $0.6 \%$ of the sensillae and even less of the neurons specific to the molecule (since we know that there are 2 to 3 ORNs per sensilla and at least 6 types of ORNs to make sense of the attractants and heterospecific deterrents - section 4.1). When this is considered along with the large variations of concentrations that would be sensed by the moth (table 6), the casting behaviour would have been observed throughout the flight of a moth attracted by conspecific pheromones. However, the ethogram of the male moth doesn't include intensive and early casting. This is another ethological argument that reinforces the need to consider the existence of an integration window in the processing of the signals generated by the ORNs.

\section{Conclusion}

Through the presentation of the moth pheromone system from an ethological perspective, this paper demonstrates the need to build lab experiments that take into account wild conditions, and the practical implications for the neuroscientists to work the natural conditions of their animal model. Salient points include the inaccuracies related to wind tunnel experiments and the use reared moth females to determine useful emission figures that would allow to understand better the pheromone field created by a swarm and inform us with more certainty about the characteristics of the integration window that seems to exist in the olfactory system of the male moth. 
This exercise required to adopt a end-to-end view of the moth pheromone system and to connect seemingly unrelated pieces of information in order to form a consistent picture. This was achieved by associating and discussing information pertaining to different species. This is indeed a key limitation of this work, and of the literature related to this topic.

The key finding of this paper is the likely existence of an integration process in the nervous system of the male moth, that allows the moth to navigate a non monotonic olfactory landscape without casting several times per second. Further work on the topic should allow to narrow down the characteristics of this integration window at long range and at close range to the swarm. It is likely that we will find that the integration window varies with the distance to the target, in a similar way the echolocation of its predator (the insectivorous bat) and the moth's auditory system adapt during the chase [57].

Supplementary Materials: The following are available online at www.mdpi.com/xxx/s1, Figure S1: title, Table S1: title, Video S1: title.

Author Contributions: Conceptualisation, methodology, software, validation, formal analysis, investigation, resources, data curation, writing - original draft preparation, review and editing: Hervé Thevenon.

Funding: This research received no external funding.

Acknowledgments: I thank the reviewers for their constructive feedbacks.

Conflicts of Interest: The authors declare no conflict of interest. 


\section{References}

1. Birch, M.C., D. Lucas, and P.R. White, The courtship behavior of the cabbage moth, Mamestra brassicae (Lepidoptera: Noctuidae), and the role of male hair-pencils. Journal of Insect Behavior, 1989. 2(2): p. 227-239.

2. Fite, G.C., Cotton fields no more: Southern agriculture, 1865-1980. 2015: University Press of Kentucky.

3. Lingren, P. and W. Wolf, Nocturnal activity of the tobacco budworm and other insects. Biometeorology in integrated pest management, 1982: p. 211-228.

4. Carde, R.T. and T.E. Hagaman, Mate location strategies of gypsy moths in dense populations. J Chem Ecol, 1984. 10(1): p. 25-31.

5. Adkisson, P.L., Weak-links in the seasonal cycle of heliothis zea and heliothis virescens which might be exploited by the sterile insect release technique, in Ecology and Behaviour of the Heliothis Complex as Related to the Sterile-male Technique. 1971, INTERNATIONAL ATOMIC ENERGY AGENCY: Vienna. p. 5-16.

6. Bennett, D.G. and J.C. Patton, A Geography of the Carolinas. 2008: Parkway Publishers, Inc.

7. Glade, E., L. Meyer, and H. Stults, The Cotton Industry in the United States - Agricultural Economic Report No. 739. 1996, Commercial Agriculture Division, Economic Research Service, U.S. Department of Agriculture.

8. Burgess, R.W., Agriculture - Chapter K, in Historical statistics of the united states. Colonial times to 1857. 1960, US Bureau of the Census.

9. Jefferson, R., H. Shorey, and L. Gaston, Sex Pheromones of Noctuid Moths. X. The Morphology and Histology of the Female Sex Pheromone Gland of Trichoplusia ni (Lepidoptera: Noctuidae) 12 . Annals of the Entomological Society of America, 1966. 59(6): p. 1166-1169.

10. Teal, P.E.a., Role of sex pheromone Heliothis in the reproductive isolation of heliothis species (Lepidoptera: Noctuidae), in Entomology and Nematology. 1981, University of Florida.

11. Jorgensen, S.E. and B. Fath, Encyclopedia of ecology. 2014: Newnes.

12. Heath, R.R., et al., Periodicity of female sex pheromone titer and release in Heliothis subflexa and $H$. virescens (Lepidoptera: Noctuidae). Annals of the Entomological Society of America, 1991. 84(2): p. 182-189 \%@ 0013-8746.

13. Ma, P.W. and W.L. Roelofs, Sex pheromone gland of the female European corn borer moth, Ostrinia nubilalis (Lepidoptera, Pyralidae): ultrastructural and biochemical evidences. Zoolog Sci, 2002. 19(5): p. 501-11.

14. Pope, M.M., L. Gaston, and T. Baker, Composition, quantification, and periodicity of sex pheromone volatiles from individual Heliothis zea females. Journal of Insect Physiology, 1984. 30(12): p. 943-945.

15. Teal, P., J. Tumlinson, and R. Heath, Chemical and behavioral analyses of volatile sex pheromone components released by callingHeliothis virescens (F.) females (Lepidoptera: Noctuidae). Journal of chemical ecology, 1986. 12(1): p. 107-126.

16. Ando, T., S.-i. Inomata, and M. Yamamoto, Lepidopteran sex pheromones, in The Chemistry of Pheromones and Other Semiochemicals I. 2004, Springer. p. 51-96.

17. Liénard, M.A., et al., Key biosynthetic gene subfamily recruited for pheromone production prior to the extensive radiation of Lepidoptera. BMC evolutionary biology, 2008. 8(1): p. 270.

18. Liénard, M.A., et al., Sex pheromone biosynthetic pathways are conserved between moths and the butterfly Bicyclus anynana. Nature communications, 2014. 5: p. 3957 \%@ 2041-1723.

19. de Fouchier, A., et al., Functional evolution of Lepidoptera olfactory receptors revealed by deorphanization of a moth repertoire. Nature communications, 2017. 8: p. 15709.

20. Liberzon, A., et al., Moth-inspired navigation algorithm in a turbulent odor plume from a pulsating source. PloS one, 2018. 13(6): p. e0198422 \%@ 1932-6203.

21. Roelofs, W.L., et al., Two sex pheromone components of the tobacco budworm moth, Heliothisvirescens. Life sciences, 1974. 14(8): p. 1555-1562.

22. Boo, K.S., et al., (Z)-9-tetradecenal: a potent inhibitor of pheromone-mediated communication in the oriental tobacco budworm moth, Helicoverpa assulta. Journal of Comparative Physiology A, 1995. 177(6): p. 695$699 \% @ 0340-7594$.

23. Vickers, N.J. and T.C. Baker, Flight of Heliothis virescens males in the field in response to sex pheromone. Physiological Entomology, 1997. 22(3): p. 277-285.

24. Vickers, N.J., The effects of chemical and physical features of pheromone plumes upon the behavioral responses of moths. Advances in Chemical Signals in Vertebrates, 1999: p. 63-76. 
25. Ming, Q.-L., Y.-H. Yan, and C.-Z. Wang, Mechanisms of premating isolation between Helicoverpa armigera (Hübner) and Helicoverpa assulta (Guenée)(Lepidoptera: Noctuidae). Journal of insect physiology, 2007. 53(2): p. 170-178\%@0022-1910.

26. Vogel, H., et al., Transcriptome analysis of the sex pheromone gland of the noctuid moth Heliothis virescens. BMC Genomics, 2010. 11: p. 29.

27. Kehat, M. and E. Dunkelblum, Behavioral responses of maleHeliothis armigera (Lepidoptera: Noctuidae) moths in a flight tunnel to combinations of components identified from female sex pheromone glands. Journal of insect behavior, 1990. 3(1): p. 75-83.

28. Zhang, J.-P., et al., An overlooked component:(Z)-9-tetradecenal as a sex pheromone in Helicoverpa armigera. Journal of insect physiology, 2012. 58(9): p. 1209-1216 \%@ 0022-1910.

29. Liu, Y., et al., Functional specificity of sex pheromone receptors in the cotton bollworm Helicoverpa armigera. PLoS One, 2013. 8(4): p. e62094.

30. Aubrey Jr, J.G., et al., Sex pheromone-producing cells and their associated cuticle in female Heliothis zea and H. virescens (Lepidoptera: Noctuidae). Annals of the Entomological Society of America, 1983. 76(3): p. 343$348 \% @ 1938-2901$.

31. Teal, P.E.A., T.C. Carlysle, and J.H. Tumlinson, Epidermal glands in terminal abdominal segments of female Heliothis virescens (F.)(Lepidoptera: Noctuidae). Annals of the Entomological Society of America, 1983. 76(2): p. 242-247\%@0013-8746.

32. J.G., K., et al., Perry's Chemical Engineer's Handbook. 8th ed. Vol. Heat and mass transfer (section 5). 1999: McGraw-Hill.

33. Geankoplis, C.J., Transport processes and separation process principles:(includes unit operations). 2003: Prentice Hall Professional Technical Reference.

34. Holmberg, M., Preliminary modelling of mass flux at the surface of plant leaves within the MELiSSA higher plant compartments., in Department of Physics and Astronomy. 2013, Uppsala University: Sweden. p. 45.

35. Shorey, H.H. and L.K. Gaston, Sex Pheromones of Noctuid Moths. VII. Quantitative Aspects of the Production and Release of Pheromone by Females of Trichoplusia ni (Lepidoptera: Noctuidae) 12 . Annals of the Entomological Society of America, 1965. 58(5): p. 604-608 \%@ 1938-2901.

36. Kaissling, K.-E., Pheromone reception in insects. The example of silk moths in Neurobiology of Chemical Communication, 2014: p. 99-146.

37. Cuperus, P.L., Distribution of antennal sense organs in male and female ermine moth, Yponomeuta vigintipunctatus (Retzius)(Lepidoptera: Yponomeutidae). International Journal of Insect Morphology and Embryology, 1983. 12(1): p. 59-66\%@0020-7322.

38. Koontz, M.A. and D. Schneider, Sexual dimorphism in neuronal projections from the antennae of silk moths (Bombyx mori, Antheraea polyphemus) and the gypsy moth (Lymantria dispar). Cell and Tissue Research, 1987. 249(1): p. 39-50\%@ 0302-766X.

39. Zhang, S., et al., Sexual dimorphism in antennal morphology and sensilla ultrastructure of Dendrolimus tabulaeformis Tsai et Liu (Lepidoptera: Lasiocampidae). Microscopy research and technique, 2013. 76(1): p. 5057\%@1097-0029.

40. Mark, C., S. Parsons, and G. Holwell, Antennal morphology and micro-sensory architecture of the New Zealand magpie moth, Nyctemera annulata (Arctiinae, Erebidae). Austral Entomology, 2017.

41. Jurenka, R.A., E. Jacquin, and W.L. Roelofs, Control of the pheromone biosynthetic pathway in Helicoverpa zea by the pheromone biosynthesis activating neuropeptide. Archives of insect biochemistry and physiology, 1991. 17(2-3): p. 81-91\%@0739-4462.

42. Richerson, J.V. and E.A. Cameron, Differences in pheromone release and sexual behavior between laboratory-reared and wild gypsy moth adults. Environmental Entomology, 1974. 3(3): p. 475-481.

43. Lopez, J.D. and J. Witz, Influence ofHeliothis virescens sex pheromone dispensers on captures ofH. zea males in pheromone traps relative to distance and wind direction. Journal of chemical ecology, 1988. 14(1): p. 265-276.

44. Thistle, H.W., et al., Surrogate pheromone plumes in three forest trunk spaces: composite statistics and case studies. Forest Science, 2004. 50(5): p. 610-625 \%@ 0015-749X.

45. Strand, T., et al., A simple model for simulation of insect pheromone dispersion within forest canopies. Ecological Modelling, 2009. 220(5): p. 640-656.

46. Seinfeld, J.H., Atmospheric Diffusion Theory. 1983. 12: p. 209-299.

47. Turner, D.B., Workbook of atmospheric dispersion estimates: an introduction to dispersion modeling. 1994: CRC press. 
48. Prueksakorn, K., et al., Review of Air Dispersion Modelling Approaches to Assess the Risk of Wind-Borne Spread of Foot-and-Mouth Disease Virus. Journal of Environmental Protection, 2012. 03(09): p. 1260-1267.

49. Kennedy, J., Zigzagging and casting as a programmed response to wind-borne odour: a review. Physiological Entomology, 1983. 8(2): p. 109-120.

50. Burns, E. and P. Teal. Antennal morphology of the male Hydraecia micacea as compared to conspecific females and male Heliothis virescens (Lepidoptera: Noctuidae). in Proceedings of the Entomological Society of Ontario. 1990.

51. Almaas, T. and H. Mustaparta, Pheromone reception in tobacco budworm moth, Heliothis virescens. Journal of chemical ecology, 1990. 16(4): p. 1331-1347.

52. Kaissling, K., Chemo-electrical transduction in insect olfactory receptors. Annual review of neuroscience, 1986. 9(1): p. 121-145.

53. Kaissling, K.-E., Olfactory perireceptor and receptor events in moths: a kinetic model. Chemical Senses, 2001. 26(2): p. 125-150\%@ 1464-3553.

54. Fuller, E.N., P.D. Schettler, and J.C. Giddings, New method for prediction of binary gas-phase diffusion coefficients. Industrial \& Engineering Chemistry, 1966. 58(5): p. 18-27 \%@ 0019-7866.

55. Kawamura, P.I. and D. Mackay, The evaporation of volatile liquids. Journal of hazardous Materials, 1987. 15(3): p. 343-364.

56. Geankoplis, C., Principles of Mass Transfer, in Transport processes and separation process principles (includes unit operations) fourth edition. 2003, Prentice Hall Press. p. 1056.

57. Thevenon, H. and G. Pfuhl, Discrepancies in the spiking threshold and frequency sensitivity of nocturnal moths explainable by biases in the canonical auditory stimulation method. R Soc Open Sci, 2018. 5(4): p. 172404. 